\title{
Mandatory costs by firm size thresholds: firm location, growth and death in Sri Lanka
}

\author{
Babatunde O Abidoye ${ }^{1}$, Peter F Orazem ${ }^{2^{*}}$ and Milan Vodopivec ${ }^{3}$
}

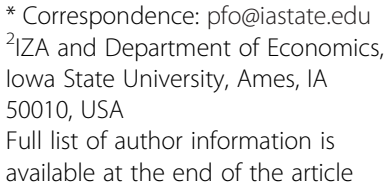

\begin{abstract}
Sri Lanka's Termination of Employment of Workmen Act (TEWA) requires that firms with 15 or more workers justify layoffs and provide generous severance pay to displaced workers, with smaller firms being exempted. Although formally subject to TEWA, firms in Export Promotion Zones (EPZs) do not face the same constraints as nonEPZ firms due to size incentives and lax labor law enforcement in that sector. In $E P Z, 77 \%$ of firms have more than 15 employees while $76 \%$ of nonEPZ firms are smaller than 15 employees. Panel data on all formal sector firms between 1995 and 2003 shows that $80 \%$ of the size gap is from sorting of large firms into the EPZ. In addition, EPZ firms grow faster and are less likely to die than comparably sized nonEPZ firms. Despite its intent, TEWA lowered employment.

JEL code: $J 30$
\end{abstract}

Keywords: Firing cost; Employment protection; Firm entry; Firm growth; Threshold; Export promotion zone; Sri Lanka

\section{Introduction}

As part of its effort to protect workers from job loss, Sri Lanka adopted the Termination of Employment of Workman Act (TEWA) in 1971. The act aimed to limit unemployment by raising the cost of layoffs. It required that each layoff of a covered worker, whether the layoff involved a single employee or a mass layoff, must be approved by the government. Until 2003, the government also determined on a case-bycase basis the level of severance pay that the firm was required to pay to the laid off workers.

Since its introduction, critics have argued that the TEWA's non-transparent, discretionary, and costly regulations discourage employment growth, hinder reallocation of labor from inefficient firms to more profitable sectors, slow the introduction of new technologies, and increase unemployment. There is at least a prima facie case that the TEWA policy has affected the size distribution of firms in Sri Lanka compared to that in 15 other developing countries reported by Leidholm and Mead (1987). Sixty-eight percent of Sri Lankan firms had 10 or fewer employees, in the top third of small firm shares in the Leidholm-Mead compilation. ${ }^{1}$ Only $12 \%$ of Sri Lanka firms had over 49 workers which would have given it the second smallest large firm share in the Leidholm-Mead listing. However, Sri Lanka's firms in Export Promotion Zones (EPZ) have a remarkably different size distribution: only $17 \%$ of the firms have 10 or fewer workers and $57 \%$ have more than 49 . Of all the countries for which we have size- 
distribution information, Sri Lanka's EPZ firms have the smallest fraction of workers in firms with fewer than 10 workers and the largest fraction of workers in firms with over 49 workers. Meanwhile, the reason the overall size distribution in Sri Lanka is weighted more heavily toward small firms is that the nonEPZ firms are so unusually small.

Micro-econometric analyses have shown that employment protection policies can have negative consequences for workers. Heckman and Pages (2000) show that in Latin America, more stringent job security laws are associated with lower employment and higher unemployment, particularly among young workers. Similarly, Besley and Burgess (2004) find that labor regulations in India had important adverse effects on output and employment. Expanding on that study, Ahsan and Pages (2009) report that regulations concerned with labor disputes and job security hurt covered workers. Bassanini and Duval (2006) find that changes in tax and labor policies explain about half of the 19822003 changes in unemployment among OECD countries. Other studies using macroeconomic data have also found negative efficiency effects of severance pay including Nickell and Layard (1999), Haffner et al. (2001), and the OECD (1999). Nevertheless, these negative findings from labor market regulations are not universal, particularly those based on cross-section analysis (Baker et al. 2005). ${ }^{2}$

This paper adds to this literature by identifying the impacts of the Sri Lanka TEWA on firm employment and growth. We exploit two sources of variation in the way firms are treated to identify the policy's effects. First, the law only applies to firms with more than 14 workers, and so smaller firms need not comply. Second, firms in EPZ do not face the same constraints imposed by the TEWA. These sharp differences in policies applied to firms of different size create several strategic options. Firms that anticipate growing beyond 14 workers will try to sort into the EPZ to avoid the constraints imposed by the law. The cost of growing beyond 14 workers may discourage nonEPZ firms from growing. Furthermore, the costs imposed by the TEWA may be large enough to drive covered firms out of business. Panel data on the cohort of all firms registering for business in Sri Lanka between 1995 and 2002 is used to provide evidence for all three possibilities.

Consistent with our theoretical predictions, we find that the potential TEWA costs result in substantially lower firm size in the nonEPZ sector, with the differential incentives to add workers inside and outside the EPZ clearly limiting growth for firms well below the threshold. EPZ firms have a 26 percentage point larger growth probability below the 14 worker employment threshold and a 14 percentage point growth advantage above the threshold. In addition, evidence is consistent with the view that the cost of adding a 15th worker implies a larger marginal cost of expansion for all nonEPZ firms below the threshold compared to nonEPZ firms already above the threshold, and so nonEPZ firms above the threshold have more rapid employment growth than nonEPZ firms below the threshold. NonEPZ firms already above the threshold are 21 percentage points more likely to add employees than are nonEPZ firms below the threshold. Finally, the results show that the biggest and most significant differences in survival probability (about 10 percentage point) is the higher exit rate of nonEPZ firms relative to EPZ firms.

The paper is organized as follows. Section 2 provides an institutional background, highlighting the intentions of the TEWA at its introduction, and its provisions and 
procedures. It also gives a description of EPZ and nonEPZ firms and description of the data. Section 3 presents the model highlighting firm entry and exit decisions. Section 4 describes the empirical section focusing on the need for analysis by firm. Section 5 presents the empirical results based on the estimation of the multinomial model of employment growth of firms. Section 6 concludes with a summary and policy recommendations.

\section{Institutional background and data descriptions}

\subsection{Termination of Employment of Workmen Act}

The TEWA was enacted at a time when Sri Lanka was pursuing isolationist economic policies including an import-substitution industrialization policy, stringent exchange controls, price controls on many commodities, and a program of nationalization of a wide-range of establishments (Ranaraja 2005). ${ }^{3}$ The TEWA applies to all firms employing 15 or more workers. For covered private firms, all terminations for any reason other than discipline are regulated by the TEWA, including redundancies arising from organizational restructuring and financial or economic constraints, temporary lay-offs, terminations as a result of the business closure, and even incompetence. ${ }^{4}$ A worker qualifies as long as he or she worked at least 180 days in the 12 month period preceding the termination.

The TEWA requires that covered employers must seek the consent of the Commissioner General of Labor (CGL) before they are allowed to dismiss workers, even if it concerns a single worker. The CGL may refuse to sanction the layoff or, if permission is granted, the employer will be required to pay severance in an amount determined by the CGL. Over the sample period, the procedure by which the severance is determined was not specified in law but was subject to a lengthy and seemingly arbitrary deliberation. In December 2003, the TEWA switched to a formula-based severance payment that is uniformly applied to all firms. While that amendment eliminated the ad hoc determination of the level of severance pay, the other elements of the policy, including the need for prior approval of layoffs, are still in place.

In dealing with termination applications by employers or complaints by workers, the CGL has the power of a District Court to conduct inquiries, such as summoning and compelling the attendance of witnesses, production of records, and recording testimony. The employer must satisfy the CGL that terminating the identified group of workers is in the best interest of the employer. While the evaluation is going on, the workers continue to be paid wages and other benefits until the CGL makes a decision, even where there is no work to be done. The final order of the CGL does not take into consideration the wages paid by the employer during the inquiry period. Data for 2003 confirm that the TEWA procedure is a very lengthy one - the average processing time of employer applications was 9.8 months, and it exceeded one year in more than 25 percent of cases (World Bank 2007).

Severance pay was quite generous. During 2002-03, the severance averaged nearly 2 times the monthly salary per year of service, and the multiple could rise as high as 6 times the monthly salary. Judged by international standards, this level of TEWA severance is extremely high. Using 2002 data, a year for which we have some data on individual compensation, we can infer the relationship between generosity of payments and years of service with the firm. A Sri Lankan worker with 20 years of service received an 
average severance package equal to 29 months of wages. In contrast, the average severance was 16 months of wages in other Asian countries, 12 months in Latin America, 7 months in Africa, 6 months in the OECD, and 4 months in transition countries. Sri Lankan workers with shorter duration of prior service were also awarded much more generous level of severance pay than workers in other countries. Since the switch to the fixed severance formula in December 2003, the program has become even more generous (World Bank 2007).

The high turnover costs imposed by the TEWA have led to a relatively small number of applications for separations by employers. Between 2000 and 2003, of more than 80 thousand covered firms, annual filings for the right to initiate a separation varied from 71 to 105 applications (World Bank 2007). Less than half of these cases were concluded by the order of the commissioner because they were settled "voluntarily", whether because the firm withdrew the application or induced the worker to retire voluntarily with retirement packages that ranged from 6 to 45 months of wages. As is apparent, it is difficult for firms to avoid the costs of the TEWA. Inflexible labor regulations were one of the five most commonly cited business challenges reported by urban firms in Sri Lanka ${ }^{5}$.

Firms in EPZ were reported to be given a preferential treatment that allowed them to limit or avoid the costs of the TEWA. Because EPZ firms were technically subject to the same regulations, the extent of the lax enforcement is difficult to quantify, but any preferential treatment should be apparent when comparing EPZ firm personnel decisions relative to those of nonEPZ firms. In addition, EPZ firms were eligible for many Board of Investments (BOI) incentives that rewarded firm growth. The size distribution of firms inside and outside the EPZ is summarized in Table 1. Large firms are atypically located in EPZ. Only 22.5\% of EPZ firms have fewer than 14 workers compared to $75.6 \%$ of nonEPZ firms! In contrast, the EPZ firms are over 3 times more likely than nonEPZ firms to have grown beyond the threshold employment level. It certainly appears that the incentives to grow must differ between the two groups of firms.

Table 1 also shows that there are apparent differences in the probability that firms increase or decrease their workforce. NonEPZ firms are much more likely than EPZ firms to reduce or maintain their current employment level, regardless of size. EPZ firms are

Table 1 Distribution of Sri Lanka firms by initial size, change in employment over the years, and EPZ status (\%), 1995 - 2003

\begin{tabular}{llllll}
\hline EPZ firms & Percent of sample & Shrink & Stay & Grow & Total \\
\hline Less than 14 workers & 22.5 & 29.3 & 26.7 & 44.0 & 100.0 \\
14 workers & 1.1 & 45.8 & 13.6 & 40.7 & 100.0 \\
More than 14 workers & 76.4 & 45.4 & 2.2 & 52.4 & 100.0 \\
Total EPZ workers = 5,441 & & & & & \\
\hline Non EPZ firms & Percent of sample & Shrink & Stay & Grow & Total \\
\hline Less than 14 workers & 75.6 & 37.2 & 40.8 & 22.0 & 100.0 \\
14 workers & 1.2 & 53.9 & 13.2 & 32.9 & 100.0 \\
More than 14 workers & 23.2 & 55.8 & 5.1 & 39.1 & 100.0 \\
Total nonEPZ workers = 320,866 & & & & & \\
\hline
\end{tabular}

Source: Authors' calculations based on the universe of all formal sector firms in Sri Lanka, 1995-2003. EPZ: Export Promotion Zone. 
much more likely to add to their employment base. The largest contrast in probability of employment growth is below the threshold: the smallest EPZ firms are twice as likely to increase employment compared to nonEPZ firms. If it is true that the cost of hiring is lower for EPZ firms, then the pattern of employment growth and decline would differ between EPZ and non-EPZ firms.

In Figure 1, we illustrate the probability of firm employment growth and decline in EPZ and nonEPZ firms around the 14-15 employee threshold. Immediately we see that EPZ firms are more likely to grow and nonEPZ firms are more likely to shrink at all firm sizes, an outcome that will prove consistent with the theory. NonEPZ firms are modestly more likely to both shrink and grow above the threshold, compared to nonEPZ firms below the threshold. In other settings, small firms are the most likely to both grow and shrink and so we would expect these lines to slope downward absent any constraints on firm choice (Evans 1987; Cabral 1995; Arkolakis 2013). The patterns for EPZ firms are harder to discern due to relatively small numbers at each firm size. It appears that EPZ firms are also more likely to grow above the threshold but there is no obvious change in the probability of firm shrinkage around the threshold.

At 14 workers where the 15th worker would trigger compliance with the TEWA, for EPZ firms the probability of employment growth decreases and the probability of firm employment decline increases. NonEPZ firms have the same pattern but the difference is only a few percentage points. The lack of massing at 14 employees outside the EPZ may seem surprising. However, firms wanting to avoid the TEWA would be expected to remain below 15 employees, but their constrained optimum employment choice may not be exactly at 14 workers. As a result, the TEWA would be expected to create higher probability of firms shrinking above the threshold and lower probability of firms growing below the threshold, a result that is supported by the patterns in Figure 1 . Moreover, data measurement errors (see above) may also contribute to less pronounced differences in observed behavior at the threshold.

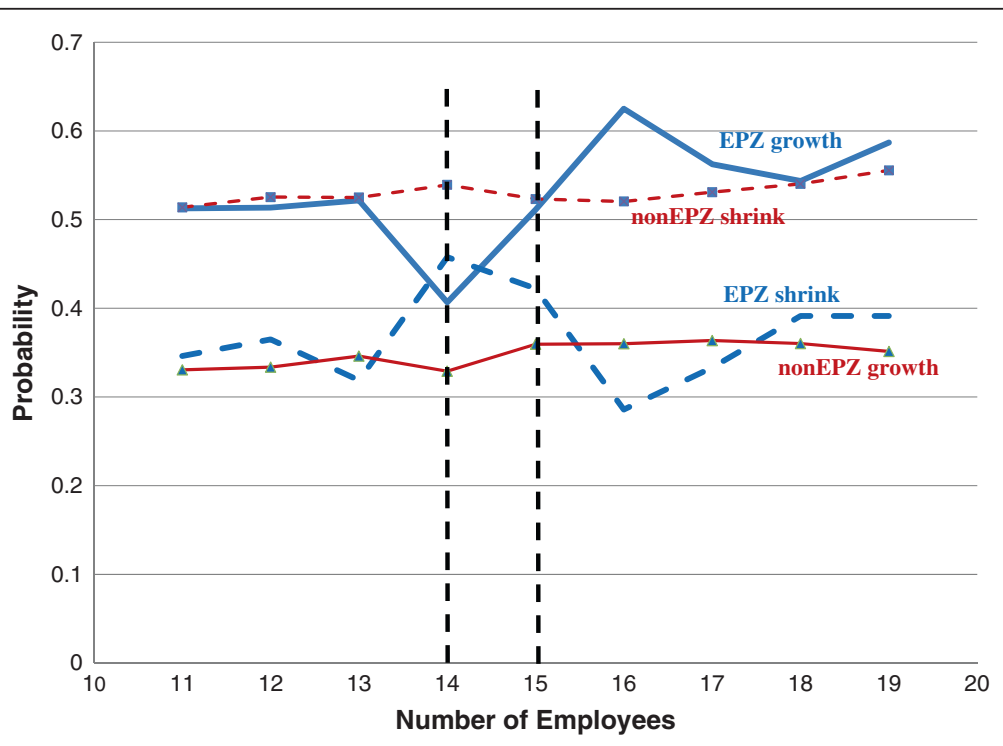

Figure 1 Probability of firm employment growth and decline above and below the 14 worker threshold, by firm size and EPZ status, 1995-2003 averages. 
To further isolate the effect of the TEWA, we need to remove the effects of firm observed and unobserved productivity attributes from the analysis. In addition, the TEWA effect will be spread across firm decisions to expand, remain at current size, or shrink in the face of external shocks. That will require a more structured analysis of the data.

\subsection{Data description}

To test for differences in firm location, growth and decline between EPZ and nonEPZ sectors, we make use of a unique panel data set that includes annual employment data for 80,560 firms in Sri Lanka over the 1995-2003 periods. The period coincides with a consistent set of restrictions on layoffs. Those policies were relaxed modestly at the end of 2003. The data are compiled by the Sri Lanka Employees' Provident Fund (EPF) on all private sector firms and workers paying contributions to the fund. All registered firms regardless of size are required to pay contributions for their workers. The data are maintained by the Central Bank of Sri Lanka.

The data are quite limited, however. Apart from the number of workers employed during the year, the only other information contained in the database is the firm's name and region: each firm is designated as having a base in one of 24 regions. The name allows us to identify which firms belong to an EPZ. The Sri Lankan Board of Investment provided us a list of names for firms that operate in EPZs. We matched these names with 1,124 firms in the EPF list, and these firms comprise our EPZ group.

The EPF data are not free of problems. The data set only contains workers for whom the firm paid contributions during the year. If for whatever reason such contributions are not paid, the true number of workers in the firm will deviate from the number reported to the EPF. The most frequent reason for such discrepancies is the presence of financial difficulties that prevent a firm from paying contributions in the current year. Even delayed payments are not used to correct the data retrospectively. Therefore, these employment numbers will only reflect the contemporaneously reported number of workers for whom the firm is making an EPF contribution. The frequency or magnitude of this measurement error is not known.

Also, the nature of the data does not allow us to differentiate between quits and layoffs and so we assume that any net loss of workers is due to layoffs. This seems reasonable, as workers who quit will presumably be replaced, resulting in no employment loss. We will discuss further in the empirical section on how we exploit the nature of the data to understand firm size decision.

The data also provide information on firms in different years. We make use of the longitudinal nature of the data to specifically identify cohorts of firms and follow their evolution over time. Thus firms that do not make contributions in 1995 but started paying contribution in 1996 are considered to be one cohort and are followed until 2003. The same is done for subsequent years. The identification of different cohorts in the data has the advantage of reducing heterogeneity and provides for a simple test of selection to explain firm size distribution and location in EPZ or nonEPZ region.

As the summary data in Table 1 reveal, there are substantial differences in average firm size and growth patterns consistent with differences in the marginal cost of hiring across the EPZ and nonEPZ regions. To evaluate the strength of that correlation more formally, we next propose a theoretical model to understand firm entry and exit decision. 


\section{Firm entry decisions: How much of the gap in size distribution between EPZ and nonEPZ firms is due to sorting by firm size at entry?} 3.1 Theory

Firms face two interrelated decisions at the time of entry designated by subscript 0: whether to locate in an EPZ zone and how much labor $\left(\mathrm{L}_{0}\right)$ and capital $\left(\mathrm{K}_{0}\right)$ to employ. We assume that there is a fixed entry cost, $F_{0}^{E P Z}$, that firms incur from attaining EPZ status. These costs would include all official and under-the-table costs of applying for and attaining EPZ status plus any additional business expenses associated with location or entry ${ }^{6}$. In exchange, the firm receives benefits from alleged lax enforcement of the TEWA and preferential tax treatment and exemption from export duties applied to worker output. That distinction sets up the comparison between EPZ and nonEPZ firms for the empirical work.

We summarize the distinction with a parameter $\delta k$ that measures the cost of compliance with the TEWA net of any benefits from being in the EPZ. The superscript $k$ denotes the cost of compliance in $E$ : EPZ or $N$ : nonEPZ. The measure of $\delta k$ is a positive or negative proportional markup over the wage. If the firm is nonEPZ, the $\delta k \geq 0$, with a positive markup if the firm has more than 14 employees so that it faces possible severance and related firing costs that are proportional to the wage. If the firm is in the EPZ, we expect $\delta^{\mathrm{E}} \leq \delta^{\mathrm{N}}$ because of lax enforcement of TEWA requirements, and $\delta^{\mathrm{E}}$ may even be negative if the firm receives tax benefits and/or subsidies tied to firm size.

All firms, EPZ or nonEPZ, have to pay market wages, $w_{0}$ and so the hourly labor cost per worker is $\mathrm{w}_{0}\left(1+\delta^{\mathrm{K}}\right)$. All nonEPZ firms with $\mathrm{L}_{0}<15$ face $\delta^{\mathrm{N}}=0$ and pay $\mathrm{w}_{0}$ per hour for labor, while all nonEPZ firms with $\mathrm{L}_{0} \geq 15$ pay $\mathrm{w}_{0}\left(1+\delta^{\mathrm{N}}\right)$ per hour; $\delta^{\mathrm{N}}>0$. All EPZ firms pay $\mathrm{w}_{0}\left(1+\delta^{\mathrm{N}}\right) \leq \mathrm{w} 0(1+\delta \mathrm{N})$ when compared with equally sized nonEPZ firms.

Assuming the firm's production function takes the Cobb-Douglas form

$$
Q_{0}=A \tau_{0} \mathrm{~L}_{0}^{\alpha_{\mathrm{L}}} \mathrm{K}_{0}^{\alpha_{\mathrm{K}}}
$$

The variable $\tau_{0}$ is a permanent exogenous technology shock to labor productivity that takes an initial value of unity. The production parameters are defined by $\mathrm{A}>0,0<\alpha_{L}<1$, and $0<\alpha_{K}<1$. Setting output price at unity and cost of capital as $r$, the firm's initial optimum input levels $\mathrm{L}_{0}^{*}$ and $\mathrm{K}_{0}^{*}$ are set by the first-order conditions:

$$
\begin{aligned}
& \alpha_{\mathrm{L}} \mathrm{A} \tau_{0} \mathrm{~L}_{0}^{\alpha_{\mathrm{L}}-1} \mathrm{~K}_{0}^{\alpha_{\mathrm{K}}}=\mathrm{w}_{0}\left(1+\delta^{\mathrm{k}}\right) \\
& \alpha_{\mathrm{K}} \mathrm{A} \tau_{0} \mathrm{~L}_{0}^{\alpha_{\mathrm{L}}} \mathrm{K}_{0}^{\alpha_{\mathrm{K}}-1}=\mathrm{r}
\end{aligned}
$$

An entering firm will decide on whether to enter the EPZ by comparing anticipated profits with and without EPZ status. For firms with $\mathrm{L}_{0}^{*}<15$, profits are higher in the nonEPZ state if $\delta^{\mathrm{E}}>0$, or if $\delta^{\mathrm{E}}<0$ and $\left|\frac{\mathrm{w}_{0} \delta^{\mathrm{E}} \mathrm{L}_{0}^{*}}{\mathrm{r}}\right|<\mathrm{F}_{0}^{\mathrm{EPZ}}$ where the term on the left of the inequality is the discounted value of the stream of anticipated EPZ subsidies. The cost advantage for small firms locating in the nonEPZ sector is that they are exempt from TEWA costs and also avoid paying $\mathrm{F}_{0}^{\mathrm{EPZ}}$. For firms with $\mathrm{L}_{0}^{*} \geq 15$, it is optimal to get EPZ status when $\mathrm{F}_{0}^{\mathrm{EPZ}}<\frac{\delta^{\mathrm{N}} \mathrm{w}_{0} \mathrm{~L}_{0}^{*}}{r}$, where the term on the right is the discounted value of the stream of anticipated TEWA payments in perpetuity. Consequently, it is possible for a firm planning to have 15 or more employees to select the nonEPZ sector. Presuming 
firms face the same market wages, capital costs, potential EPZ benefits, and potential TEWA costs, the firms most likely to sort into the EPZ sector have the largest initial employment levels, $\mathrm{L}_{0}^{*}$.

This simple model shows that small firms will tend to sort into nonEPZ and large firms into EPZ at the time of entry, conditional on prevailing wages, capital costs and technology. That suggests that empirical analysis of the size distribution of firms must compare firms facing the same prices and technologies at the time of entry. Moreover, empirical studies have consistently shown that firm growth rates and death rates are initially both slow with firm age and so we need to standardize firm age to generate accurate transition probabilities (Evans 1987; Cabral 1995; Arkolakis 2013). These arguments dictate our use of cohorts of newly born firms for our analysis.

\subsection{Evidence of the impact of sorting on the gap in firm size between EPZ and nonEPZ}

Table 2 provides summary information on the size distribution of firms in EPZ and nonEPZ regions for successive entry cohorts from 1996 through 2002. Recall that the overall percentage of firms with at least 15 employees is $76 \%$ in the EPZ and $23 \%$ in the nonEPZ (see Table 1). The proportion of EPZ firms already above 14 workers at entry varies between $53 \%$ and $70 \%$ with an average of $62 \%$. It is apparent that the EPZ firms quickly add workers with the fraction above 15 workers rising $2.5 \%$ per year averaged across the cohorts. If $76 \%$ is taken as the final percentage of firms employing over 15 workers, sorting of large firms into EPZ is responsible for about $80 \%$ of the EPZ size distribution.

In the nonEPZ sector, only $9 \%$ of the firms in a cohort start with at least $15 \mathrm{em}$ ployees, and the fraction actually decrease through the first few years. By 2003, $8 \%$ of these seven firm entry cohorts had 15 or more workers. It is apparent that the nonEPZ firms do not grow as readily as the EPZ firms. While we cannot argue with certainty that the proximate cause is the TEWA, the results are consistent with the predicted impact of the TEWA on firm entry decisions.

There is a 53 percentage point gap between the worker distribution of EPZ and nonEPZ firms in the population as shown in Table 1. The average gap at entry between large EPZ and nonEPZ firms is also 53 percentage points as shown in Table 2. However, the population measure excludes firms that have died, while the cohort estimates

Table 2 Distribution of EPZ and non EPZ firms at entry (1996) and the end of sample (2003)

\begin{tabular}{|c|c|c|c|c|c|c|c|}
\hline & $\begin{array}{l}\% \text { large } \\
\text { at entry, } \\
\text { EPZ }\end{array}$ & $\begin{array}{l}\% \text { large } \\
\text { in 2003, } \\
E P Z\end{array}$ & $\begin{array}{l}\% \text { large } \\
\text { at entry, } \\
\text { non EPZ }\end{array}$ & $\begin{array}{l}\% \text { large } \\
\text { in 2003, } \\
\text { non EPZ }\end{array}$ & $\begin{array}{l}\text { \% of large } \\
\text { firms at entry } \\
\text { that is EPZ }\end{array}$ & $\begin{array}{l}\text { \% of large } \\
\text { firms in } 2003 \\
\text { that is EPZ }\end{array}$ & $\begin{array}{l}\text { \% of firms } \\
\text { in EPZ at } \\
\text { entry }\end{array}$ \\
\hline 1996 & 55 & 71 & 11 & 9 & 6 & 10 & 1 \\
\hline 1997 & 67 & 72 & 12 & 10 & 7 & 9 & 1 \\
\hline 1998 & 62 & 68 & 10 & 8 & 9 & 12 & 2 \\
\hline 1999 & 65 & 67 & 8 & 7 & 10 & 11 & 1 \\
\hline 2000 & 70 & 76 & 11 & 10 & 9 & 10 & 1 \\
\hline 2001 & 53 & 65 & 8 & 7 & 8 & 10 & 1 \\
\hline 2002 & 60 & 65 & 8 & 8 & 9 & 11 & 1 \\
\hline Average & 62 & 69 & 9 & 8 & 8 & 10 & 1 \\
\hline
\end{tabular}

Source: Authors' calculations based $\mathrm{n}$ the universe of all formal sector firms in Sri Lanka, 1995-2003. EPZ: Export Promotion Zone. 
at entry include all firms. It is possible that the fraction of firms with over 15 employees will grow because small firms add workers over time, or it may be that the fraction increases because small firms are more likely to die. As we will see, sorting at entry is an important source of the difference between EPZ and nonEPZ firm size distributions, but differential growth and death rates also play a role.

\section{Can the TEWA affect firm employment growth and death?}

\subsection{Theory}

When firms commit to their initial capital stock and decide whether or not to enter the EPZ, they do not know the future path of prices and technology. Having committed to a capital stock and a location, their response to these changing economic circumstances is limited to labor adjustments in the short run. At some future time, $t$, the condition setting their short-run employment level will be

$$
\alpha_{\mathrm{L}} \mathrm{A} \tau_{\mathrm{t}} \mathrm{L}_{\mathrm{t}}^{\alpha_{\mathrm{L}}-1} \mathrm{~K}_{0}^{* \alpha_{\mathrm{K}}} \geq \mathrm{w}_{\mathrm{t}}\left(1+\delta^{\mathrm{k}}\right)
$$

The firm's optimal labor allocation is conditioned on the initial capital investment at entry. It is also affected by the evolution of technology, $\mathrm{\tau}_{\mathrm{t}}$, and wages, $\mathrm{w}_{\mathrm{t}}{ }^{7}$

We let technology evolve according to:

$$
\ln \left(\tau_{\mathrm{t}}\right)=\ln \left(\mathrm{\tau}_{\mathrm{t}-1}\right)+\overline{\eta_{0}}+\eta_{\mathrm{t}} ; \eta_{\mathrm{t}} \sim \mathrm{N}\left(0, \sigma_{\eta}^{2}\right)
$$

The variable $\overline{\eta_{0}}$ is the trend growth in technology known by all firms at the time of entry, but $\eta_{t}$ is an unforeseeable but permanent technology innovation that the firm cannot control. This specification for $\tau_{t}$ presumes that the firm's labor productivity is a random walk process about the trend. We assume similarly that market wages $\left(\mathrm{w}_{\mathrm{t}}\right)$ evolve according to a random walk process with a known $\mathrm{drift}^{8}$ so that

$$
\ln \left(\mathrm{w}_{\mathrm{t}}\right)=\ln \left(\mathrm{w}_{\mathrm{t}-1}\right)+\bar{\omega}_{0}+\omega_{\mathrm{t}} ; \omega_{\mathrm{t}} \sim \mathrm{N}\left(0, \sigma_{\omega}^{2}\right)
$$

The variable $\bar{\omega}_{0}$ is the trend growth in wages known by all firms at the time of entry, but $\omega_{t}$ is an unforeseeable but permanent innovation in wages that the firm cannot control.

We can model the changes in the firm's employment decisions by applying $3 \mathrm{~A}-\mathrm{C}$ to two successive years and solving for the change in desired labor. From here on, we define the notional firm input demand that would hold at an interior solution in period $t$ as $\mathrm{L}_{\mathrm{t}}^{*}$ and $\mathrm{K}_{\mathrm{t}}^{*}$. The form of the decision depends on whether the firm comes under the TEWA policy. We examine several cases that will illustrate the range of possible responses to the TEWA system. Recall that we are assuming that EPZ firms are exempt from all TEWA requirements in forming these responses, an assumption that we will test with the data.

\subsubsection{Case 1: Firm is exempt from TEWA with $\delta^{N}=0$ and $\delta^{E} \leq 0$ in both periods with $\mathrm{L}_{\mathrm{t}-1}^{*}<15$ and $\mathrm{L}_{\mathrm{t}}^{*}<15$}

Assuming interior solutions, the change in desired labor is governed by $\ln \left(\frac{L_{t}}{L_{t-1}}\right)=\frac{\eta_{t}-\omega_{t}}{\left(1-\alpha_{L}\right)}$. The firm is not constrained by the severance policy and adjusts labor upward with positive labor productivity shocks and negative wage shocks. If EPZ firms receive favorable subsidies so that $\delta^{\mathrm{E}}<0$, comparable adverse shocks are less likely to cause the left hand side of 
(3A) to fall below the right-hand side for EPZ firms compared to nonEPZ firms. As a consequence, below the threshold, nonEPZ firms are more likely to shrink or less likely to expand compared to EPZ firms.

\subsubsection{Case 2: Firm is covered by TEWA so $\delta^{N}>\delta^{E>}<0$ in both periods because $\mathrm{L}_{\mathrm{t}-1}^{*} \geq 15$ and $\mathrm{L}_{\mathrm{t}}^{*} \leq 15$}

Assuming interior solutions, the change in desired labor is also governed by $\ln \left(\frac{L_{t}}{L_{t-1}}\right)=\frac{\eta_{t}-\omega_{t}}{\left(1-\alpha_{\mathrm{L}}\right)}$ and so optimal labor demand responds as with the exempt firms in Case 1. However, even at their optimum labor allocations, the nonEPZ firms face a constant disadvantage of having higher labor costs and more distorted capital labor ratios compared to their EPZ competitors. As before, comparable adverse shocks are more likely to lead to violations of the first order condition (3A) for nonEPZ firms than EPZ firms. In addition, even if they are at their optimum labor allocation, nonEPZ firm profit levels will be lower than that of comparably sized EPZ firms because of their higher labor costs. As a result, above the threshold, nonEPZ firms are more likely to shrink and less likely to expand compared to equally sized EPZ firms.

\subsubsection{Case 3: Firm has $\mathrm{L}_{\mathrm{t}-1}^{*} \geq 15$ and considers remaining below the threshold in period $\mathrm{t}$ even though $L_{t}^{*} \leq 15$ if the firm is exempt from the TEWA}

In this case, assume first that employment in $t-1$ is fixed by the interior solution of $3 \mathrm{~A}-\mathrm{C}$ such that $\mathrm{L}_{\mathrm{t}-1}^{*}<15$. However, in the next period, the firm's optimal staffing would move it into the covered region:

$$
\begin{aligned}
& \alpha_{\mathrm{L}} \mathrm{At}_{\mathrm{t}} \mathrm{L}_{\mathrm{t}}^{\alpha_{\mathrm{L}}-1} \mathrm{~K}_{0}^{* \alpha_{\mathrm{K}}}=\mathrm{w}_{\mathrm{t}} \rightarrow \mathrm{L}_{\mathrm{t}}^{*} \geq 15 \\
& \alpha_{\mathrm{L}} \mathrm{A} \tau_{\mathrm{t}} \mathrm{L}_{\mathrm{t}}^{* \alpha_{\mathrm{L}}-1} \mathrm{~K}_{0}^{* \alpha_{\mathrm{K}}}<\mathrm{w}_{\mathrm{t}}\left(1+\delta^{\mathrm{k}} \mathrm{L}_{\mathrm{t}}^{*}\right) ; \forall \mathrm{L}_{\mathrm{t}}^{*} \geq 15 ; \delta>0
\end{aligned}
$$

This is the case where the firm would want to expand beyond 14 employees if it faced the market wage alone. However, in moving beyond 14 employees, the firm has to pay for the TEWA severance system for all $\mathrm{L}_{\mathrm{t}}^{*}$ workers, leading to an even larger increase in the marginal cost of adding any workers beyond 14. As a consequence, the firm will set their staffing at some second-best level $\mathrm{L}_{\mathrm{t}}<15$ and where the marginal product $\alpha_{\mathrm{L}} A \tau_{\mathrm{t}} \mathrm{L}_{\mathrm{t}}^{\alpha_{\mathrm{L}}-1} \mathrm{~K}_{0}^{* \alpha_{\mathrm{K}}}>\mathrm{w}_{\mathrm{t}} .{ }^{9}$ Because $\delta^{\mathrm{N}}>\delta^{\mathrm{E}}$, it is more likely that nonEPZ firms will decide not to expand beyond 14 workers compared to EPZ firms.

\subsection{Empirical framework}

The discussion illustrates that the TEWA can alter the incentives for nonEPZ firms to expand or shrink compared to similarly sized EPZ firms. Both above and below the threshold, the combination of special tax and subsidy treatments from the EPZ and the costs of compliance with the TEWA create conditions that increase the likelihood that nonEPZ firms will shrink or fail to grow compared to their EPZ counterparts. At the threshold, nonEPZ firms are more likely to face additional labor costs that cause them to remain below the threshold. As we show in this section, these predictions can be tested with longitudinal data on cohorts of firms entering business at the same time.

The use of a common startup date is important for two reasons. First, all firms will be exposed to the same information on wages, technology and macroeconomic 
conditions, greatly simplifying the specification of common shocks. Second, a sample of the universe of all starting firms avoids the selection bias that would exist had we been constrained to a sample of surviving firms in which the weakest would have been already eliminated.

The empirical section described below can be viewed in the difference-in-differences framework, using firms at or above the severance threshold as the treatment group, and those with fewer than 14 workers and those in EPZs as control groups. The first control group follows naturally from the design of the TEWA system, because the regulations do not apply to firms employing less than 15 workers. The second control group is formed based on the assumption that enforcement is ineffective in EPZs, allowing firms to escape paying separation costs as dictated by TEWA.

\subsubsection{Measuring the TEWA effect on probability of firm growth}

We begin by applying an interior solution to (3A) which defines the firm's notional demand in period $t$ as

$$
\left(\alpha_{\mathrm{L}}-1\right) \ln \mathrm{L}_{\mathrm{t}}^{*}=\ln \left(\frac{\mathrm{w}_{\mathrm{t}}\left(1+\delta^{\mathrm{k}}\right)}{\alpha_{\mathrm{L}} \mathrm{At}_{\mathrm{t}} \mathrm{K}_{0}^{* \alpha_{\mathrm{K}}}}\right)
$$

The first order condition for notional employment in period $t+1$ is

$$
\left(\alpha_{\mathrm{L}}-1\right) \ln \mathrm{L}_{\mathrm{t}+1}^{*}=\ln \left(\frac{\mathrm{w}_{\mathrm{t}+1}\left(1+\delta^{\mathrm{k}}\right)}{\alpha_{\mathrm{L}} \mathrm{A} \tau_{\mathrm{t}+1} \mathrm{~K}_{0}^{* \alpha_{\mathrm{K}}}}\right)=\left(\alpha_{\mathrm{L}}-1\right) \ln \mathrm{L}_{\mathrm{t}}^{*}+\omega_{\mathrm{t}+1}-\eta_{\mathrm{t}+1}
$$

where we apply (4A), (3B) and (3C). Rearranging, we have that the change in notional employment from $t$ to $t+1$ is

$$
\ln \left(\frac{\mathrm{L}_{\mathrm{t}+1}^{*}}{\mathrm{~L}_{\mathrm{t}}^{*}}\right)=\frac{\overline{\eta_{0}}+\eta_{\mathrm{t}+1}-\overline{\omega_{0}}-\omega_{\mathrm{t}+1}}{\left(1-\alpha_{\mathrm{L}}\right)}
$$

which means that if firm employment evolves without frictions, the change in notional employment will be a random walk with drift. Employment increases with trend growth and unexpected innovations in technology and decreases with expected wage increases and positive wage shocks. Importantly, the firm-specific Hicksian productivity factor $A$ is differenced away, and so labor demand or supply shifts related to firm-specific unobservable productivity, firm location, or industry are held constant in the frictionless solution. However, the constraints on maximization caused by the TEWA will mean that actual firm employment growth will deviate from the frictionless outcome. The greater frictions in the nonEPZ sector should be apparent when we compare employment changes in those firms with the less constrained employment growth in the EPZ sector above, at and below the threshold.

This simple model does not take into account the stylized facts about firm growth by firm age and size. Our assessment of the literature suggests that these tendencies are unlikely to cause faster growth in the EPZ sector. First, as noted above, firm growth rates tend to decrease with firm age (Evans 1987; Cabral 1995; Arkolakis 2013). This will not bias comparisons across EPZ and nonEPZ firms, but it will induce a downward trend in longitudinal firm growth rates within the sectors. Potentially of greater concern is a second stylized result that exporting firms tend to grow faster than non- 
exporting firms which could bias the comparison across the EPZ and nonEPZ firms. However, extensive reviews of the empirical literature by Wagner (2007), Wagner (2012) and Singh (2010) suggest that the productivity advantage to exporting firms is driven by the sorting of more efficient firms into the export sector, similar to our own finding that larger firms enter the EPZ sector while smaller firms enter the nonEPZ sector. In contrast, there is no consistent evidence that the act of exporting raises firm growth rates. Again, these past findings suggest that the comparison across EPZ and nonEPZ sectors will not be biased by the act of exporting after controlling for the initial conditions at time of entry. In fact, evidence suggests that the highest firm growth rates among exporting firms are concentrated among the very small firms, while larger firms have growth rates near zero (Arkolakis 2013). If true, the bias would actually go against finding faster growth rates in the EPZ sector as firm size increases.

Actual employment changes for the ith firm are modeled as an approximation to the firm's notional employment changes as

$$
\begin{aligned}
\ln \left(\frac{\mathrm{L}_{\mathrm{it}+1}}{\mathrm{~L}_{\mathrm{it}}}\right)= & \beta_{0}+\beta_{\mathrm{EPZ}} \mathrm{EPZ}_{\mathrm{i}}+\beta_{\mathrm{L}^{-}} \mathrm{E}_{\mathrm{it}}^{\mathrm{L}^{-}}+\beta_{\mathrm{L}^{+}} \mathrm{E}_{\mathrm{it}}^{\mathrm{L}^{+}}+\left\{\gamma_{\mathrm{L}^{-}} \mathrm{E}_{\mathrm{it}}^{\mathrm{L}^{-}}+\gamma_{\mathrm{L}^{+}} \mathrm{E}_{\mathrm{it}}^{\mathrm{L}^{+}}\right\} * \mathrm{EPZ}_{\mathrm{i}} \\
& +\frac{\eta_{\mathrm{i} 0}^{-}-\overline{\omega_{\mathrm{i} 0}}}{\left(1-\alpha_{\mathrm{L}}\right)}+\frac{\eta_{\mathrm{it}+1^{-}}-\omega_{\mathrm{it}+1}}{\left(1-\alpha_{\mathrm{L}}\right)}
\end{aligned}
$$

This specification adds terms to (5) that allow differential responses to the wage and technology shocks depending on whether the firm is inside or outside the EPZ and whether its employment level lies above or below the threshold. The constant $\beta_{0}$ corresponds to the base case which is set to be the anticipated employment change at a firm with $\mathrm{L}_{\mathrm{it}}=14$ in a nonEPZ region. The other possible employment levels in period $\mathrm{t}$ are indicated by a dummy variable $\mathrm{E}_{\mathrm{it}}^{\mathrm{L}^{-}}$when employment is below 14 and $\mathrm{E}_{\mathrm{it}}^{\mathrm{L}^{+}}$when employment is above 14. The corresponding coefficients differentiate between employment growth effects below the threshold $\left(\beta_{\mathrm{L}^{-}}\right)$and above the threshold $\left(\beta_{\mathrm{L}^{+}}\right)$. The dummy variable $E P Z_{i}$ indicates that the firm is in an export promotion zone. Given the other parameters, the coefficient $\beta_{\mathrm{EPZ}}$ measures the difference in employment growth between EPZ and nonEPZ firms at the threshold $L_{i t}=14$. The $\gamma_{L^{-}}$capture additional differences in employment growth between EPZ and nonEPZ below the threshold and $\gamma_{\mathrm{L}^{+}}$measures additional differences between the sectors above the threshold. If EPZ firms face fewer frictions in employment adjustments because of partial or full immunity from the TEWA or other benefits associated with EPZ status, $\gamma_{\mathrm{L}^{-}}$and $\gamma_{\mathrm{L}^{+}}$will be positive and significant. The $\gamma_{\mathrm{L}^{-}}$and $\gamma_{\mathrm{L}^{+}}$may differ from one another if there are different relative regulatory costs between EPZ and nonEPZ sectors above and below the threshold.

Our last requirement to estimate (6) is to operationalize the random walk and drift terms. The wage and technology trend terms are firm-specific and reflect information known at the time of entry. We approximate these terms by $\frac{\eta_{\mathrm{i} 0}-\omega_{\overline{\mathrm{i}}}}{\left(1-\alpha_{\mathrm{L}}\right)}=\phi_{\mathrm{L}} \ln \left(\mathrm{L}_{\mathrm{i} 0}\right)+\phi_{0}$ where the initial employment level reflects the firm's anticipated input needs based on what the firm knew at the time of entry and the second term is a cohort-specific term reflecting common expectations of the drift terms held by all firms entering at the same time. The second term requires that we control for a common fixed effect for all firms in the entry cohort. Inclusion of these terms helps to control for nonrandom sorting into firm size groups across firms and across entry cohorts. 
The random walk terms are i.i.d. errors when we estimate one period employment changes. We let $\epsilon_{\mathrm{it}}^{\Lambda}=\frac{\eta_{\mathrm{it}+1^{-}}-\omega_{\mathrm{it}+1}}{\left(1-\alpha_{\mathrm{L}}\right)}$ be the composite error term in the employment change relationship. If $\epsilon_{\mathrm{it}}^{\Lambda}$ is distributed extreme value, then (6) can be posed as a multinomial logit specification. If we further define the term $\Delta \Lambda_{t+1}$ as a trichotomous variable and define the right-hand side terms excluding $\epsilon_{\mathrm{it}}$ as $\mathrm{Z}_{\mathrm{it}}^{\prime} \mathrm{B}^{\Lambda}$, the estimable variant of (6) that will yield the parameters of interest is

$$
\begin{gathered}
\Delta \Lambda_{\mathrm{t}+1}=1 \text { if } \ln \left(\frac{\mathrm{L}_{\mathrm{it}+1}}{\mathrm{~L}_{\mathrm{it}}}\right)-\mathrm{Z}_{\mathrm{it}}^{\prime} \mathrm{B}^{\Lambda}<\epsilon_{\mathrm{it}}^{\Lambda} \\
\Delta \Lambda_{\mathrm{t}+1}=2 \text { if } \ln \left(\frac{\mathrm{L}_{\mathrm{it}+1}}{\mathrm{~L}_{\mathrm{it}}}\right)-\mathrm{Z}_{\mathrm{it}}^{\prime} \mathrm{B}^{\Lambda}=\epsilon_{\mathrm{it}}^{\Lambda} \\
\Delta \Lambda_{\mathrm{t}+1}=3 \text { if } \ln \left(\frac{\mathrm{L}_{\mathrm{it}+1}}{\mathrm{~L}_{\mathrm{it}}}\right)-\mathrm{Z}_{\mathrm{it}}^{\prime} \mathrm{B}^{\Lambda}>\epsilon_{\mathrm{it}}^{\Lambda}
\end{gathered}
$$

Table 3 summarizes the identification and interpretation of the coefficients. The first column shows the parameters describing firm growth for EPZ firms below, at and above the threshold. The second column shows the corresponding parameter estimates for nonEPZ firms. The first differences of the nonEPZ estimates allow us to identify $\beta_{\mathrm{L}}$ and $\beta_{\mathrm{L}^{+}}$. The double difference allows us to identify $\gamma_{\mathrm{L}^{-}}$and $\gamma_{\mathrm{L}^{+}} \cdot \beta_{\mathrm{L}^{-}}>0$ indicates faster growth than the base case for nonEPZ firms below 14 workers. Similarly, $\beta_{\mathrm{L}^{+}}>0$ indicates faster employment growth than the base case for nonEPZ firms above 14 workers. $\beta_{\mathrm{EPZ}}+\gamma_{\mathrm{L}^{-}}>0$ indicates that EPZ firms are growing faster than nonEPZ firms below 14 workers and $\beta_{\mathrm{EPZ}}+\gamma_{\mathrm{L}^{+}}>0$ indicates that EPZ firms are growing faster than nonEPZ firms above 14 workers. The coefficient $\beta_{\text {EPZ }}$ tells us if EPZ firms grow faster than nonEPZ firms at the threshold. These coefficient estimates form the basis of our hypothesis tests.

\subsubsection{Measuring the TEWA effect on probability of Firm Death}

Even with perfect foresight, firms will not completely avoid the TEWA costs by sorting into or out of the EPZ. NonEPZ firms face a labor cost disadvantage every period because $\delta^{\mathrm{N}} \geq \delta^{\mathrm{E}}$ both above and below the threshold. Because nonEPZ firms will pay an artificially high labor cost per hour, they will pick an inefficiently high ratio of capital

\begin{tabular}{|c|c|c|c|}
\hline \multirow[b]{2}{*}{ Employment in period $t$} & \multicolumn{2}{|l|}{ Type of firm } & \multirow[b]{2}{*}{ Difference } \\
\hline & $\overline{E P Z}$ & Non EPZ & \\
\hline \multicolumn{4}{|c|}{ Firm employment growth effects below the threshold } \\
\hline $\mathrm{E}_{\mathrm{it}}^{\mathrm{L}^{-}}=1: \mathrm{L}_{\mathrm{it}-1} \leq 13$ & $\beta_{L^{-}}+\beta_{E P Z}+\gamma_{L^{-}}$ & $\beta_{L^{-}}$ & $\beta_{E P Z}+\gamma_{L^{-}}$ \\
\hline$L_{i t}=14$ & $\beta_{E P Z}$ & reference & $\beta_{E P Z}$ \\
\hline Difference & $\beta_{L^{-}}+\gamma_{L^{-}}$ & $\beta_{L^{-}}$ & $\gamma_{L^{-}}$ \\
\hline \multicolumn{4}{|c|}{ Firm employment growth effects above the threshold } \\
\hline $\mathrm{E}_{\mathrm{it}}^{\mathrm{L}^{+}}=1: \mathrm{L}_{\mathrm{it}} \geq 15$ & $\beta_{L^{+}}+\beta_{E P Z}+\gamma_{L^{+}}$ & $\beta_{\mathrm{L}^{+}}$ & $\beta_{E P Z}+\gamma_{L^{+}}$ \\
\hline$L_{i t}=14$ & $\beta_{E P Z}$ & reference & $\beta_{E P Z}$ \\
\hline Difference & $\beta_{L^{+}}+\gamma_{L^{+}}$ & $\beta_{L^{+}}$ & $\gamma_{L^{+}}$ \\
\hline
\end{tabular}
per worker. The higher input costs than their EPZ competitors also leave them more

Table 3 Parameters controlling the probability of employment growth by type of firms

EPZ: Export Promotion Zone. 
exposed to adverse wage or technology shocks, increasing the probability that nonEPZ firms will shrink or fail.

We can test the hypothesized greater likelihood of firm death for nonEPZ firms using a similar specification as in (7) but with an alternative dependent variable. The details of the parameterizations follow exactly from the previous section except that the expected signs are opposite those for firm growth. We denote the composite error term as $\epsilon_{\mathrm{it}}^{\Upsilon}=\frac{\eta_{\mathrm{it}+1}-\omega_{\mathrm{it}+1}}{\left(1-\alpha_{\mathrm{L}}\right)}$ which we assume is distributed extreme value. Then, we can derive a binomial logit specification for firm deaths which are indicated by unit values of the dichotomous variable $\Delta \Upsilon_{\mathrm{T}+1}$. Denoting the terms on the right-hand side of (7) excluding the error as $Z_{i t}^{\prime} B^{\Upsilon}$, we can define firm deaths by

$$
\begin{gathered}
\Delta \Upsilon_{\mathrm{t}+1}=1 \text { if } \ln \left(\frac{\mathrm{L}_{\mathrm{it}+1}}{\mathrm{~L}_{\mathrm{it}}}\right)-\mathrm{Z}_{\mathrm{it}}^{\prime} \mathrm{B}^{\mathrm{Y}} \leq \epsilon_{\mathrm{it}}^{\mathrm{Y}} \\
\Delta \Upsilon_{\mathrm{t}+1}=0 \text { if } \ln \left(\frac{\mathrm{L}_{\mathrm{it}+1}}{\mathrm{~L}_{\mathrm{it}}}\right)-\mathrm{Z}_{\mathrm{it}}^{\prime} \mathrm{B}^{\mathrm{Y}}>\epsilon_{\mathrm{it}}^{\mathrm{Y}}
\end{gathered}
$$

where a firm death occurs when the notional reduction in staffing from year $t$ to $t+1$ is sufficiently large that it is more profitable for the firm to exit than to remain in operation with reduced staffing. If the additional costs faced by nonEPZ firms are sufficiently large compared to EPZ firms, then we would find negative values for $\beta_{\mathrm{EPZ}}, \gamma_{\mathrm{L}^{-}}$and $\gamma_{\mathrm{L}^{+}}$.

\section{Can the TEWA affect firm employment growth and death?}

In Table 4 and Table 5, we present the results of our estimation of the firm employment growth and firm death equations, estimated over the pooled firm entry cohorts from 1996 through 2002. These firms are followed annually until 2003, and so their growth and decline is tracked from one to seven years after entry. Constant terms for cohort year of birth are used to correct for the common information on macroeconomic conditions that shape anticipated price, wage and technology trends at the time of entry. The firm's initial employment level is used as a proxy for firm-specific information on technologies and wages that shaped the initial profit maximizing employment level. These parameters are estimated, but not reported ${ }^{10}$.

For ease of interpretation, all estimated coefficients are converted into their implied transition probabilities. Therefore, all results reported in Table 4 and Table 5 reflect the marginal effects by EPZ or nonEPZ status of the prior year's employment level on the probability of employment growth, decline, or firm death. We report the reduced form coefficients in the upper panel and the lower panel presents the values of the hypotheses tests and the test statistics.

\subsection{Employment growth and decline inside and outside the EPZ}

The reduced form parameters give the average annual probability of employment growth relative to the reference firm which is a nonEPZ firm with 14 employees in year $t$. Smaller EPZ firms are 9 percentage points more likely to add workers than the reference firm. In contrast, smaller nonEPZ firms are nearly 17 percentage points less likely to add workers than a reference firm! Therefore, the differential incentives to add workers inside and outside the EPZ clearly limit growth for firms well below the threshold. As indicated in the theory section, there is no reason to believe that the 
Table 4 Reduced form and structural estimates of the probability of employment growth conditional on prior employment level inside and outside Enterprise Protection Zones as per equation (6) using Probit model with cluster robust standard errors

\begin{tabular}{ll}
\hline Reduced form parameters: $\mathrm{EPZ}_{\mathbf{i}}=\mathbf{1}$ & Marginal effect $^{\mathbf{a}}$ \\
\hline $\mathrm{L}_{\mathrm{it}} \leq 13, \mathrm{E}_{\mathrm{it}}^{\mathrm{L}^{-}}=1: \beta_{\mathrm{L}^{-}}+\beta_{\mathrm{EPZ}}+\gamma_{\mathrm{L}^{-}}$ & $0.089^{* *}(0.023)$ \\
$\mathrm{L}_{\mathrm{it}}=14: \beta_{\mathrm{EPZ}}$ & $0.123(0.079)$ \\
$\mathrm{L}_{\mathrm{it}} \geq 15, E_{\mathrm{it}}^{L^{+}}=1: \beta_{\mathrm{L}^{+}}+\beta_{\mathrm{EPZ}}+\gamma_{\mathrm{L}^{+}}$ & $0.190^{* *}(0.019)$ \\
Reduced form parameters: $E P Z_{\mathrm{i}}=0$ & \\
$\mathrm{~L}_{\mathrm{it}} \leq 13, \mathrm{E}_{\mathrm{it}}^{L^{-}}=1: \beta_{\mathrm{L}^{-}}$ & $-0.166^{* *}(0.015)$ \\
$\mathrm{L}_{\mathrm{it}}=14:$ reference & - \\
$\mathrm{L}_{\mathrm{it}} \geq 15, \mathrm{E}_{\mathrm{it}}^{L^{+}}=0: \beta_{\mathrm{L}^{+}}$ &
\end{tabular}

Structural estimates

Hypothesis: Relative to nonEPZ firms of like size and vintage...

$\beta_{\text {EPZ }}>0$ : EPZ firms grow faster at the threshold

$\beta_{E P Z}+\gamma_{L^{-}}>0$ : EPZ firms grow faster below the threshold

$\beta_{E P Z}+\gamma_{L^{+}}>0$ : EPZ firms grow faster above the threshold

Hypothesis: Relative to same sector firms below the threshold...

$\beta_{\mathrm{L}^{+}}-\beta_{\mathrm{L}^{-}}>0$ : nonEPZ firms grow faster above the threshold

$\left(\beta_{L^{+}}+\gamma_{L^{+}}\right)-\left(\beta_{L^{-}}+\gamma_{L^{-}}\right)>0$ : EPZ firms grow faster above the threshold

Hypothesis: Relative to EPZ firms at the threshold....

$Y_{L^{-}}=0$ : EPZ firms grow at a different rate below the threshold

$\mathrm{Y}_{\mathrm{L}^{+}}=0$ : EPZ firms grow at a different rate above the threshold

$0.020(0.01)$

Log-likelihood value of -94817.0 with $79 \%$ of the observation predicted correctly.

${ }^{a}$ Marginal effect reported with attached standard error in parenthesis.

${ }^{b}$ Marginal effect reported with attached Chi-square statistic in parentheses. Critical value is 3.84 at the .05 significance level.

*significance at the 0.1 level. ${ }^{* *}$ significance at the .05 level.

EPZ: Export Promotion Zone.

constrained optimal employment level for a firm facing a substantial added cost of employing 15 workers would be 14 workers. This finding suggests that potential TEWA costs result in substantially lower firm size in the nonEPZ sector, even for firms well below the 14 firm threshold.

Above the threshold, EPZ firms are 19 percentage points more likely to add workers than the reference nonEPZ firm with 14 workers. In contrast, nonEPZ firms already above the threshold are 5 percentage points more likely to add workers than the reference firm. Because firm adding a 15th worker face additional costs on all 15 workers, we would expect a larger marginal cost to expansion for firms at the threshold compared to those already above the threshold.

Turning to the structural estimates, EPZ firms at the threshold are 12 percentage points more likely to add workers than the reference nonEPZ firm at the threshold, a difference that easily meets any standard significance criteria. The hypothesis that EPZ firms grow faster than comparably sized nonEPZ firms in the same entry cohort either above or below the threshold also passes any standard significance criteria. These effects are not small: 26 percentage point larger growth probability for firms below the threshold and a 14 percentage point growth advantage for firms above the threshold. This is overwhelming support of the hypothesis that firms in the EPZ grow faster than firms with identical initial size and year of entry in the nonEPZ sector. 
Table $\mathbf{5}$ Reduced form and structural estimates of the probability of firm death conditional on prior employment level inside and outside Enterprise Protection Zones as per equation (7) using Probit model with cluster robust standard errors

\begin{tabular}{|c|c|}
\hline Reduced form parameters: $\mathrm{EPZ}_{\mathrm{i}}=1$ & Marginal effect ${ }^{\mathrm{a}}$ \\
\hline $\mathrm{L}_{\mathrm{it}} \leq 13, \mathrm{E}_{\mathrm{it}}^{\mathrm{L}^{-}}=1: \beta_{\mathrm{L}^{-}}+\beta_{\mathrm{EPZ}}+\gamma_{\mathrm{L}^{-}}$ & $-0.073^{* *}(0.011)$ \\
\hline$L_{i t}=14: \beta_{E P Z}$ & $-0.032(0.062)$ \\
\hline $\mathrm{L}_{\mathrm{it}} \geq 15, \mathrm{E}_{\mathrm{it}}^{\mathrm{L}^{+}}=1: \beta_{\mathrm{L}^{+}}+\beta_{\mathrm{EPZ}}+\gamma_{\mathrm{L}^{+}}$ & $-0.093^{* *}(0.009)$ \\
\hline \multicolumn{2}{|l|}{ Reduced form parameters: $E P Z_{i}=0$} \\
\hline $\mathrm{L}_{\mathrm{it}} \leq 13, \mathrm{E}_{\mathrm{it}}^{\mathrm{L}^{-}}=1: \beta_{\mathrm{L}^{-}}$ & $0.023^{* *}(0.011)$ \\
\hline $\mathrm{L}_{\mathrm{it}}=14$ : reference & - \\
\hline $\mathrm{L}_{\mathrm{it}} \geq 15, \mathrm{E}_{\mathrm{it}}^{\mathrm{i}^{+}}=0: \beta_{\mathrm{L}^{+}}$ & $0.004(0.012)$ \\
\hline \multicolumn{2}{|l|}{ Structural estimates } \\
\hline Hypothesis: Relative to nonEPZ firms of like size and vintage... & Marginal effect ${ }^{\mathrm{b}}$ \\
\hline$\beta_{E P Z}<0$ : EPZ firms survive more readily at the threshold & $-0.032^{* *}(66.4)$ \\
\hline$\beta_{E P Z}+\gamma_{L^{-}}<0$ : EPZ firms survive more readily below the threshold & $-0.096^{* *}(72.6)$ \\
\hline$\beta_{E P Z}+Y_{L^{+}}<0:$ EPZ firms survive more readily above the threshold & $-0.096^{* *}(30.1)$ \\
\hline \multicolumn{2}{|l|}{ Hypothesis: Relative to firms in the same sector below the threshold... } \\
\hline$\beta_{\mathrm{L}^{+}}-\beta_{\mathrm{L}^{-}}<0$ : nonEPZ firms survive more readily above the threshold & $-0.022(1.22)$ \\
\hline$\left(\beta_{L^{+}}+\gamma_{L^{+}}\right)-\left(\beta_{L^{-}}+\gamma_{L^{-}}\right)<0$ : EPZ firms survive more readily above the threshold & $-0.020(0.266)$ \\
\hline \multicolumn{2}{|l|}{ Hypothesis: Relative to EPZ firms at the threshold.... } \\
\hline$V_{L^{-}}=0:$ EPZ firms below the threshold have a different survival rate & $-0.064(1.22)$ \\
\hline $\mathrm{Y}_{\mathrm{L}^{+}}=0$ : EPZ firms above the threshold have a different survival rate & $-0.065(1.66)$ \\
\hline
\end{tabular}

The TEWA costs tend to keep nonEPZ firms small. NonEPZ firms below the threshold are 17 percentage points less likely to grow than are firms at the threshold, defying the tendency for firm growth rates to decrease with firm size. In contrast, EPZ firms below the threshold are more likely to add workers, consistent with the unconstrained pattern of firm growth by size found elsewhere. nonEPZ firms that manage to cross the threshold are 5\% more likely to grow than the firms at the threshold who face very large marginal costs of the 15th worker, and are 21 percentage points more likely to add employees than are nonEPZ firms below the threshold. In contrast, there are no significant differences between employment growth probabilities of EPZ firms at or above the threshold. The differences in growth probability between EPZ above and below the threshold are only marginally significant. In short, growth rates for EPZ firms are quite similar to the unconstrained random walk with drift, while the pattern for nonEPZ firms is very different from the typical pattern of the fastest growth rates concentrated among the smallest firms.

\subsubsection{Firm death inside and outside the EPZ}

Table 5 reports the marginal probabilities of firm exit by current firm size and sector. EPZ firms below and above the threshold are 7 and 9 percentage points less likely to 
exit in a given year compared to comparably sized nonEPZ firms of the same vintage. At the threshold, EPZ firms are 3 percentage points less likely to exit but the estimate is not precise. NonEPZ firms below the threshold are the most likely to die at a 2 percentage point elevated exit rate per year. NonEPZ firms above the threshold have the same exit probability as firms at the threshold.

The structural hypothesis tests demonstrate a higher risk of death for almost all nonEPZ firms, regardless of size. The one-tailed test that EPZ firms are more likely to survive than nonEPZ firms at the threshold is not definitive. However, firms below the threshold have a 10 percentage point higher probability of death than comparably sized EPZ frims. For firms above the threshold, again there is a 10 percentage point higher probability of exit for nonEPZ firms. All of these estimates easily passes critical values. Greater exposure to the TEWA expenses and other disadvantages of nonEPZ firms relative to EPZ firms of comparable initial size and vintage increases significantly the likelihood that nonEPZ firms will fail.

For both EPZ and nonEPZ sectors, there is a small advantage of size - about a two percentage point lower risk of death per year relative to smaller firms in the same sector. However, the difference is only statistically significant for the nonEPZ sector. In addition, we cannot reject the null hypothesis of a uniform firm survival probability above and below the threshold in the EPZ sector. Therefore, survival probability does not change significantly by firm size in the EPZ, but small nonEPZ firms do face a higher probability of failure compared to other nonEPZ firms. However, the biggest and most significant differences in survival probability is the higher exit rate in nonEPZ relative to EPZ firms of equal initial size and vintage.

\subsubsection{Placebo tests}

We reestimated the model of firm employment growth used in Table 4 but using alternate artificial threshold sizes of $\mathrm{L}_{\mathrm{it}}=20$ and $\mathrm{L}_{\mathrm{it}}=30$. For these placebo regressions, we limit the sample to firms above 14 workers to take out the effect of the actual threhold. The results are reported in Table 6 with the Table 4 results repeated in the first column. The results in column 1 are very different from those in the last two columns. Probability of firm growth in the nonEPZ sector below the threshold are now not significantly different from the probability at the placibo threshold (at the threshold of 20) or positive (at the threshold of 30) rather than negative. The differences in growth rates for nonEPZ firms above and below the threshold are now only 4-5 percentage points compared to the 21 percentage points using the true thresholds. However, the EPZ firms continue to have a growth advantage over their nonEPZ counterparts consistent with the expected lower cost of employment expansion in the EPZ sector at all employment levels. In addition, EPZ firms grow at equal rates above and below the placebo thresholds which is consistent with the expected growth pattern for the EPZ sector for firms above the true threshold. In short, the EPZ firms continue to act as expected with the placebo thresholds while the nonEPZ firms look markedly different from their behavior about the true thresholds. These findings buttress the validity of the findings in Table 4.

\section{Conclusion}

Numerous studies have explained the effect of labor market restriction on unemployment, employment growth and wage inequality in OECD countries. This study extends 
Table 6 Reduced form and structural estimates of the probability of employment growth conditional on prior employment level inside and outside Enterprise Protection Zones as per equation (6) using Probit model with cluster robust standard errors

\begin{tabular}{|c|c|c|c|}
\hline Reduced form parameters: $\mathrm{EPZ}_{\mathrm{i}}=1$ & $\begin{array}{l}T=14^{a} \text { from } \\
\text { Table } 4\end{array}$ & $\begin{array}{l}\text { Placebo } 1: T=20^{a} \\
\text { Sample excludes } L_{i t}<15\end{array}$ & $\begin{array}{l}\text { Placebo 2: } T=30^{a} \\
\text { Sample excludes } L_{i t}<15\end{array}$ \\
\hline $\mathrm{L}_{\mathrm{it}} \leq \mathrm{T}-1, \mathrm{E}_{\mathrm{it}}^{L^{-}}=1: \beta_{\mathrm{L}^{-}}+\beta_{\mathrm{EPZ}}+\gamma_{\mathrm{L}^{-}}$ & $0.09^{* *}(0.02)$ & $0.23^{* * *}(0.05)$ & $0.25^{* * *}(0.03)$ \\
\hline $\mathrm{L}_{\mathrm{it}}=\mathrm{T}: \beta_{\mathrm{EPZ}}$ & $0.12^{*}(0.08)$ & $0.31^{* * *}(0.10)$ & $0.36^{* * *}(0.10)$ \\
\hline $\begin{array}{l}L_{i t} \geq T+1, E_{i t}^{L_{i t}^{+}}=1: \beta_{L^{+}}+\beta_{E P Z}+\gamma_{L^{+}} \\
\text {Reduced form parameters: } E P Z_{i}=0\end{array}$ & $0.19^{* *}(0.02)$ & $0.20^{* * *}(0.01)$ & $0.22^{* * *}(0.01)$ \\
\hline $\mathrm{L}_{\mathrm{it}} \leq \mathrm{T}-1, \mathrm{E}_{\mathrm{it}}^{\mathrm{L}^{-}}=1: \beta_{\mathrm{L}^{-}}$ & $-0.17^{* *}(0.02)$ & $0.01(0.01)$ & $0.04^{* * *}(0.01)$ \\
\hline$L_{i t}=T$ : reference & - & - & - \\
\hline $\mathrm{L}_{\mathrm{it}} \geq T+1, \mathrm{E}_{\mathrm{it}}^{L^{+}}=0: \beta_{\mathrm{L}^{+}}$ & $0.048^{* *}(0.01)$ & $0.049^{* * *}(0.01)$ & $0.08^{* * *}(0.01)$ \\
\hline
\end{tabular}

Structural estimates

Hypothesis: Relative to nonEPZ firms of like size and vintage ${ }^{b}$

\begin{tabular}{|c|c|c|c|}
\hline $\begin{array}{l}\beta_{E P Z}>0 \text { : EPZ firms grow faster at the } \\
\text { threshold }\end{array}$ & $0.123^{* *}(224)$ & $0.31^{* *}(5.7)$ & $0.36^{* *}(18)$ \\
\hline $\begin{array}{l}\beta_{E P Z}+\gamma_{L^{-}}>0 \text { : EPZ firms grow faster } \\
\text { below the threshold }\end{array}$ & $0.255^{* *}(161)$ & $0.219^{* *}(21.63)$ & $0.21^{* *}(49.4)$ \\
\hline $\begin{array}{l}\beta_{E P Z}+\gamma_{L^{+}}>0 \text { : EPZ firms grow faster } \\
\text { above the threshold }\end{array}$ & $0.142^{* *}(2952)$ & $0.15^{* *}(131)$ & $0.14^{* *}(101)$ \\
\hline \multicolumn{4}{|c|}{ Hypothesis: Relative to same sector firms below the threshold ${ }^{b}$} \\
\hline $\begin{array}{l}\beta_{\mathrm{L}^{+}}-\beta_{\mathrm{L}^{-}}>0 \text { : nonEPZ firms grow faster } \\
\text { above the threshold }\end{array}$ & $0.214^{* *}(21)$ & $0.048^{* *}(22.6)$ & $0.04 * *(17.65)$ \\
\hline $\begin{array}{l}\left(\beta_{L^{+}}+\gamma_{L^{+}}\right)-\left(\beta_{L^{-}}+\gamma_{L^{-}}\right)>0 \text { : EPZ firms } \\
\text { grow faster above the threshold }\end{array}$ & $0.101^{* *}(42)$ & $-0.03(42)$ & $-0.03(0.60)$ \\
\hline \multicolumn{4}{|c|}{ Hypothesis: Relative to EPZ firms at the threshold ${ }^{\mathrm{b}}$} \\
\hline $\begin{array}{l}Y_{L^{-}}=0: \text { : EPZ firms grow at a different } \\
\text { rate below the threshold }\end{array}$ & $0.133^{*}(3.5)$ & $-0.08(3.5)$ & $-0.15(0.14)$ \\
\hline $\begin{array}{l}Y_{L^{+}}=0 \text { : EPZ firms grow at a different } \\
\text { rate above the threshold }\end{array}$ & $0.020(0.01)$ & $-0.15(0.01)$ & $-0.22(0.43)$ \\
\hline
\end{tabular}

${ }^{a}$ Marginal effect reproted with attached standard error in parenthesis.

${ }^{b}$ Marginal effect reported with attached Chi-square statistic in parentheses. Critical value is 3.84 at the .05 significance level.

${ }^{*}$ significance at the 0.1 level, ${ }^{* *}$ significance at the .05 level, ${ }^{* * *}$ significance at the .01 level.

EPZ: Export Promotion Zone.

this inquiry to the case of employment protection in a developing country context, namely the TEWA in Sri Lanka. The program imposes severance costs on firms with 15 or more workers in Sri Lanka, but not on smaller firms or firms in export promotion zones (EPZ).

We find that the size distribution of firms differs dramatically across the EPZ and nonEPZ sectors, with $76 \%$ of nonEPZ firms having less than 15 workers while $77 \%$ of EPZ firms have at least 15 employees. Using panel data on employment in the universe of formal sector firms in Sri Lanka from 1995 to 2003, we found evidence that 62\% of EPZ firms open for business with at least 15 employees compared to only $9 \%$ of nonEPZ firms. That implies that disproportionate sorting of large firms into EPZ explains about $80 \%$ of the gap in firm size distribution across EPZ and nonEPZ sectors. Moreover, EPZ firms above the threshold are 14 percentage points more likely to add workers than are comparably sized nonEPZ firms, while EPZ firms below the threshold have an astounding 26 percentage point higher probability of growing relative to their nonEPZ counterparts. While the large firm share of nonEPZ firms rises over time, even 
that turns out to be due to poor outcomes in the nonEPZ sector. Small nonEPZ firms are slightly more likely to exit than nonEPZ firms which lowers the small firm share of all nonEPZ firms over time. In fact, small and large nonEPZ firms are 10 percentage points more likely to die than are their EPZ counterparts of like size and vintage.

The totality of the evidence suggests that the TEWA restrictions on firing that were supposed to increase employment stability had exactly the opposite result. By imposing a tax on firm growth, the system causes nonEPZ firms to inefficiently limit employment, increasing the odds that the firm will fail. While large firms atypically sort into the EPZ and avoid the regulatory expenses, a significant number of firms are caught by the regulatory costs. Results suggest that these firms would hire more workers and be more likely to succeed if nonEPZ and EPZ firms operated under the same, more liberal rules regarding the costs of hiring and firing.

\section{Endnotes}

${ }^{1}$ Sri Lanka data were compiled from the universe of formal sector firms in Sri Lanka described later in the paper.

${ }^{2}$ Freeman (2008) presents a review of both theoretical and empirical effects of labor market institutions. Addison and Teixeira (2001) review findings regarding the effects of employment protection legislation.

${ }^{3}$ The rationale for the policy, as stated in the Industrial Policy of Ceylon (1971), was that "....the [Government] is pledged to the establishment of a socialist society. This commitment calls for major changes in industrial policy to eliminate some of the social and economic consequences of the policy followed in the past few years [such as] the concentration of monopoly power in the hands of a few investors, leading to gross inequalities in the distribution of income and the entrenchment of privileged groups in society ... [and] the heavy reliance of local industry on imported raw material, components and technology....".

${ }^{4}$ Incompetence is not considered a disciplinary matter. Even in the case of disciplinary layoffs due to misconduct or poor discipline, the employer must inform the worker in writing of the reasons for such termination before the second day after such termination, failing which, the worker is entitled to seek redress under the TEWA on the basis that the termination of his services was not for disciplinary reasons.

${ }^{5}$ The others were an unreliable supply of electricity; uncertain government policy; macroeconomic instability; and the high cost of obtaining external financing (World Bank 2005).

${ }^{6}$ We should note that we have no evidence that the application for EPZ status is anything but above board. We are just trying to be complete in allowing for supra-normal application costs.

${ }^{7}$ The technology shock could also include innovations in the real price of output. To economize on terms, we fix the output price at unity and let all changes in the value of labor time work their way through productivity shocks.

${ }^{8}$ Ashenfelter and Card (1982) showed that wages evolve according to an AR(1) process with first-order coefficient insignificantly different from 1, and so the random walk assumption is not a radical departure from reality.

${ }^{9}$ In the Cobb-Douglas formulation used here, and with the restriction that capital is fixed, the second best solution is to set employment at 14. A more general specification could result in the second best employment level at less than 14 . 
${ }^{10}$ In practice, our main parameters of interest were not sensitive to the inclusion or exclusion of these cohort and firm-specific entry conditions.

\section{Competing interests}

The IZA Journal of Labor \& Development is committed to the IZA Guiding Principles of Research Integrity.

The authors declare that they have observed these principles.

\section{Acknowledgements}

The authors wish to thank the Central Bank of Sri Lanka for providing data and to Ramani Gunatilaka for providing useful comments to earlier drafts of the paper.

Responsible editor: David Lam

\section{Author details}

${ }^{1}$ Department of Agricultural Economics, Extension and Rural Development, University of Pretoria, Pretoria 0002, South Africa. ${ }^{2}$ IZA and Department of Economics, lowa State University, Ames, IA 50010, USA. ${ }^{3}$ IZA, International School for Social and Business Studies, Celje, Slovenia and University of Primorska, Faculty of Management, Koper, Slovenia.

Received: 9 July 2014 Accepted: 17 November 2014

Published online: 31 December 2014

\section{References}

Addison JT, Teixeira P (2001) "The Economics of Employment Protection". In: IZA Discussion Paper no. 381. Institute for the Study of Labor, Bonn, Germany

Ahsan A, Pages C (2009) Are All Labor Regulations Equal? Evidence from Indian Manufacturing. J Comp Econ 37(1):62-75

Arkolakis C (2013) A Unified Theory of Firm Selection and Growth. Yale University Working Paper, New Haven, CT

Ashenfelter O, Card D (1982) Time Series Representations of Economic Variables and Alternative Models for the Labour Market. Review Econ Stud 49(1):761-781

Baker D, Glyn A, Howell D, Schmitt J (2005) "Labor Market Institutions and Unemployment: A Critical Assessment of the Cross-Country Evidence". In Fighting Unemployment: The Limits of Free Market Orthodoxy, ed. David R. Howell. Oxford University Press, Oxford

Bassanini A, Duval R (2006) "Employment Patterns In OECD Countries: Reassessing the Role of Policies and Institutions". In: OECD Economics Department Working Paper No. 486

Besley T, Burgess R (2004) Can Labor Regulation Hinder Economic Performance? Evidence from India. Q J Econ 119(1):91-134

Cabral L (1995) Sunk Costs, Firm Size and Firm Growth. J Ind Econ 43(2):161-172

Evans DS (1987) The Relationship Between Firm Growth, Size, and Age: Estimates for 100 Manufacturing Industries. $J$ Ind Econ 35(4):567-581

Freeman RB (2008) Labor Market Institutions around the World. In: Blyton P, Bacon N, Fiorito J, Heery E (eds) The SAGE Handbook of Industrial Relations. SAGE Publications Ltd., London

Haffner R, Nickell S, Nicoletti G, Scarpetta S, Zoega G (2001) "European Integration, Liberalization and Labour Market Performance". In: Bertola G, Boeri T, Nicoletti G (eds) Welfare and Employment in a United Europe. The MIT Press, Cambridge, MA

Heckman JJ, Pages C (2000) The Cost of Job Security Regulation: Evidence from Latin American Labor Markets. Economia 1(1):109-154

Leidholm C, Mead D (1987) "Small-Scale Industries in Developing Countries: Empirical Evidence and Policy Implications". In: International Development Paper 9. Agricultural Economics Department, Michigan State University,

Nickell S, Layard R (1999) "Labor Market Institutions and Economic Performance". In: Ashenfelter O, Card D (eds) Handbook of Labor Economics, vol 3, chapter 46, 1st edn. Elsevier, Amsterdam pp 3029-3084

OECD (1999) OECD Employment Outlook 1999. OECD, Paris

Ranaraja S (2005) "The Functioning of the Termination of Employment Act Of 1971". In: World Bank, HDNSP, processed Singh T (2010) Does international trade cause economic growth? A survey. World Econ 33(11):1517-1564

Wagner J (2007) Exports and productivity: A survey of the evidence from firm-level data. World Econ 30(1):60-82

Wagner J (2012) International trade and firm performance: a survey of empirical studies since 2006. Rev World Econ 148(2):235-267

World Bank (2005) "Sri Lanka: Improving The Rural And Urban Investment Climate". In: World Bank, Poverty Reduction and Economic Management Network, South Asia Region

World Bank (2007) "Sri Lanka: Strengthening Social Protection". In: World Bank, Human Development Unit, South Asia Region, Report No. 38197-LK 